\title{
Estudo da gestão da produção agrícola familiar na comunidade Canaã, Paço do
}

\section{Lumiar, Maranhão, Brasil}

Study on family agricultural production in the community of Canaã, Paço do Lumiar, Maranhão,

\section{Brazil}

Estudio sobre producción agrícola familiar en la comunidad de Canaã, Paço do Lumiar,

\section{Maranhão, Brasil}

Recebido: 04/08/2021 | Revisado: 13/08/2021 | Aceito: 14/08/2021 | Publicado: 16/08/2021

ORCID: https://orcid.org/0000-0002-5080-8521

Faculdade Supremo Redentor, Brasil

E-mail: klingerduarte@hotmail.com

Yuri Nascimento Fróes

ORCID: https://orcid.org/0000-0002-0928-0980 Instituto Florence de Ensino Superior, Brasil

E-mail: yurifroes@outlook.com

Wallace Ribeiro Nunes Neto

ORCID: https://orcid.org/0000-0002-6614-6745

Universidade Federal do Maranhão, Brasil

E-mail: wallaceneto2010@hotmail.com

Erika Luana Lima Durans

ORCID: https://orcid.org/0000-0002-7111-1184

Universidade CEUMA, Brasil

E-mail: erika_durans@hotmail.com

Paulo Henrique Azevedo Lima

ORCID: https://orcid.org/0000-0001-5835-5670

Universidade CEUMA, Brasil

E-mail: paulo247484@ ceuma.com.br

Luciano Freato

ORCID: https://orcid.org/0000-0002-4652-8025 Universidade CEUMA, Brasil

E-mail: lucianofreato@gmail.com

Sandra Regina Gusmão da Hora

ORCID: https://orcid.org/0000-0003-4451-4487 Universidade CEUMA, Brasil

E-mail: sadrareginahora@hotmail.com

Joicy Cortez de Sá Sousa

ORCID: https://orcid.org/0000-0001-8678-0244 Universidade CEUMA, Brasil E-mail: joicyvet@hotmail.com

Darlan Ferreira da Silva

ORCID: https://orcid.org/0000-0001-7091-8077 Universidade CEUMA, Brasil

E-mail: darlanveggito@hotmail.com

Delmo Mattos da Silva

ORCID: https://orcid.org/0000-0002-9074-2192

Universidade Federal do Maranhão, Brasil

E-mail: delmomattos@hotmail.com

Wellyson da Cunha Araújo Firmo ORCID: https://orcid.org/0000-0002-6979-1184 Universidade CEUMA, Brasil

E-mail: well.firmo@gmail.com

Maria Raimunda Chagas Silva

ORCID: https://orcid.org/0000-0002-8685-7608 Universidade CEUMA, Brasil E-mail: marirah@gmail.com

\section{Resumo}

O sistema agrícola familiar funciona como uma unidade socioprodutiva e que necessita de auxílio para o seu desenvolvimento, como organização nas funções administrativas e produtivas. Este processo requer uma gestão do sistema, alinhamento e planejamento para tomada de decisão. Esta pesquisa analisou a importância do planejamento 
estratégico na gestão da produção e distribuição de agricultores familiares na região do Paço do Lumiar, Maranhão, Brasil. A área de estudo localiza-se na região de Nova Canaã, município de Paço do Lumiar. Foram selecionadas seis famílias de agricultores familiares que utilizam a mesma área de plantio. A obtenção dos dados deu-se por meio de formulário de entrevista. Além disso foram coletados quatro pontos amostrais do solo de produção agrícola, no período de setembro a novembro de 2019. Foram analisadas as características físico-químicas do solo no Laboratório de Ciências Ambientais da Universidade CEUMA (LACAM). Dessa forma, pôde-se traçar o perfil empreendedor dos estabelecimentos agrícolas familiares estudados, analisando suas dificuldades e facilidades dentro do seu planejamento estratégico. A partir dos dados coletados, juntamente com as análises físico-químicas do solo, foi possível traçar um fluxograma para melhoria da gestão de negócios para melhoria no desempenho da produção do agricultor, características físico-químicas do solo e pela análise SWOT o desenvolvimento de um Planejamento Estratégico eficiente para as famílias. Acredita-se que modelo de gestão adequado garante uma melhor utilização do solo, redução de custos e aumento da lucratividade para o pequeno agricultor.

Palavras-chave: Agricultura familiar; Gestão; Análise SWOT; Solo.

\begin{abstract}
The family agricultural system works as a socio-productive unit that needs help for its development, as an organization in administrative and productive functions. This process requires system management, alignment and planning for decision making. This research analyzed the importance of strategic planning in managing the production and distribution of family farmers in the region of Paço do Lumiar, Maranhão, Brazil. The study area is in the region of Nova Canaã, municipality of Paço do Lumiar. Six families of family farmers who use the same planting area were selected. Data collection took place through an interview form. In addition, four sampling points of agricultural production soil were collected from September to November 2019. The physical-chemical characteristics of the soil were analyzed at the Laboratory of Environmental Sciences at the University CEUMA (LACAM). Thus, it was possible to trace the entrepreneurial profile of the studied family farms, analyzing their difficulties and facilities within their strategic planning. From the collected data, together with the physical-chemical analysis of the soil, it was possible to draw a flowchart for improving business management to improve the performance of the farmer's production, physical-chemical characteristics of the soil and by SWOT analysis the development of an Efficient Strategic Planning for Families. It is believed that an adequate management model ensures better land use, cost reduction and increased profitability for the small farmer.
\end{abstract}

Keywords: Family farming; Management; SWOT analysis; Ground.

\title{
Resumen
}

El sistema agrícola familiar funciona como una unidad socio-productiva que necesita ayuda para su desarrollo, como una organización en funciones administrativas y productivas. Este proceso requiere gestión, alineación y planificación del sistema para la toma de decisiones. Esta investigación analizó la importancia de la planificación estratégica en la gestión de la producción y distribución de los agricultores familiares en la región de Paço do Lumiar, Maranhão, Brasil. El área de estudio está ubicada en la región de Nova Canaã, municipio de Paço do Lumiar. Se seleccionaron seis familias de agricultores familiares que utilizan la misma área de siembra. La recolección de datos se realizó a través de un formulario de entrevista. Además, se recolectaron cuatro puntos de muestreo de suelo de producción agrícola de septiembre a noviembre de 2019. Las características fisicoquímicas del suelo fueron analizadas en el Laboratorio de Ciencias Ambientales de la Universidad CEUMA (LACAM). Así, fue posible trazar el perfil emprendedor de las explotaciones familiares estudiadas, analizando sus dificultades y facilidades dentro de su planificación estratégica. A partir de los datos recolectados, junto con el análisis fisicoquímico del suelo, fue posible trazar un diagrama de flujo para mejorar la gestión empresarial para mejorar el desempeño de la producción del agricultor, características fisicoquímicas del suelo y mediante análisis SWOT el desarrollo de una Planificación Estratégica Eficiente para las Familias. Se cree que un modelo de gestión adecuado asegura un mejor uso de la tierra, reducción de costos y mayor rentabilidad para el pequeño agricultor.

Palabras clave: Agricultura familiar; Administración; Análisis SWOT; Suelo.

\section{Introdução}

Toda estrutura organizacional tem como estratégia definir modelos gerenciais apropriados e específicos para seu desenvolvimento e, na Agricultura Familiar, visa melhorar as práticas de gestão, contribuindo com a definição de um modelo de produção mais adequado (Baiardi \& Alencar, 2014). Com o passar dos anos, a agricultura familiar passou por várias mudanças, e um dos principais fatores responsáveis por esse processo foi o aumento da competitividade, que fez com que o processo da gestão fosse aperfeiçoado para realizar os negócios de uma forma mais ágil e dinâmica (Carvalho \& Lima, 2015).

No Maranhão há 692 mil pessoas são ocupadas em atividades agropecuárias, reflexo da relevância que a agricultura familiar tem para a economia do estado maranhense e a importância do conhecimento de propriedades intrínsecas a este ramo, 
como se organizam e em qual cenário se encontram quando o assunto é a gestão da produção (P. B. Silva et al., 2008).

Há uma dificuldade para a gestão organizacional das famílias de agricultores, pois não há uma divisão clara no nível estratégico, tático e operacional, no modelo de produção, gerenciamento e gestão para auxílio à tomada de decisão (Joffre \& Simon, 2012; Thiago et al., 2020). Sendo fundamental para, tal melhora, um bom gerenciamento de custos, pois com uma gestão de custos bem estruturada, o processo de tomada de decisões torna-se mais assertivo e seguro, contribuindo para a obtenção de bons resultados externos das organizações, isto é, os pontos fortes e fracos, e, as oportunidades e ameaças em seu ambiente de trabalho (Mintzber, 2007; Thiago et al., 2020).

A área estudada, denominada "Comunidade Vila Residencial Nova Canaã", é resultado do remanejamento da comunidade Vila Madureira, criada na área correspondente à parte do território das instalações da Usina Termoelétrica (UTE). Os moradores foram deslocados para uma área de $25.000 \mathrm{~m}^{2}$, no município de Paço do Lumiar - MA, pertencente ao entorno da Região Metropolitana de São Luís, a uma distância de 30 km do centro da capital (Antunes et al., 2001; De \& Morais, 2017; Moreira, 2014).

O processo de reassentamento compulsório dos moradores da antiga Vila Madureira para a Vila Residencial Nova Canaã ocorreu em duas etapas: a primeira em 9 de outubro de 2009, quando 50 famílias foram retiradas da Vila Madureira; a segunda no mês de dezembro do mesmo ano, em que 45 famílias foram deslocadas para a Vila Residencial Nova Canaã, totalizando 95 casas para abrigar as 95 famílias (Cláudia Cardoso Corrêa \& Rosa Marques, 2017).

O ambiente agrícola está condicionado a fatores sazonais e incontroláveis, como o clima, os preços de insumos derivados de mercados concorrentes e preparação adequada do solo o que exige talento, conhecimento e uso de distintas ações visando minimizar as perdas e maximizar os ganhos no interior das organizações deste setor, o que torna necessário desenvolver um planejamento estratégico para auxiliar na tomada de decisão (Carlos et al., 2019; Wollmann \& Galvani, 2013). Conforme Parizotto Seidler \& Fritz Filho, (2016), a inovação nos insumos agrícolas, auxilia o produtor a reduzir as perdas e aumentar sua participação no mercado comunitário.

Tendo em vista a dificuldade enfrentada para a gestão organizacional dessas famílias, foi necessário o desenvolvimento e compreensão de modelo de gestão em propriedades rurais familiares através do mapeamento da utilização das melhores práticas por meio da Análise Estratégica SWOT (do inglês, "Strenghts", "Weaknesses", "Opportunities" e “Threats”) (Biassio \& Silva, 2015). Esta análise pode comtemplar aspectos intrínsecos da metodologia das culturas de hortaliças e promover uma melhoria dos processos produtivos e de comercialização, que ocupam o maior espaço organizacional, independentemente do tamanho ou do ramo da organização (Mintzber, 2007).

O diagnóstico de fertilidade do solo é uma ferramenta pouco explorada e que pode promover o melhor aproveitamento dos recursos de uma unidade de produção agrícola, aumentando sua produtividade e qualidade e manter uma o plantio com planejamento, inovação, tecnologia e estratégias adequadas ao ambiente de negócios (Fajnzylber, P.; Sarti, F.; Leal, 1993; Valarini Et Al., 2011).

Esta pesquisa deseja evidenciar as abordagens sobre gestão agrícola das famílias residentes na comunidade Canaã para melhoria do planejamento na gestão agrícola conforme as características do ambiente, do solo e de recursos financeiro.

\section{Metodologia}

A comunidade Nova Canaã está localizada no município de Paço do Lumiar, Estado do Maranhão (limite oeste); limite à Norte, com a rodovia MA-204; ao Sul, com a Avenida Epitáfio Cafeteira; à Leste, com o Cemitério Pax União. O mapa de localização da área de estudo e os pontos de coleta do solo e de plantio das hortaliças está explanado na Figura 1. 
Figura 1. Mapa da área de produção agrícola.

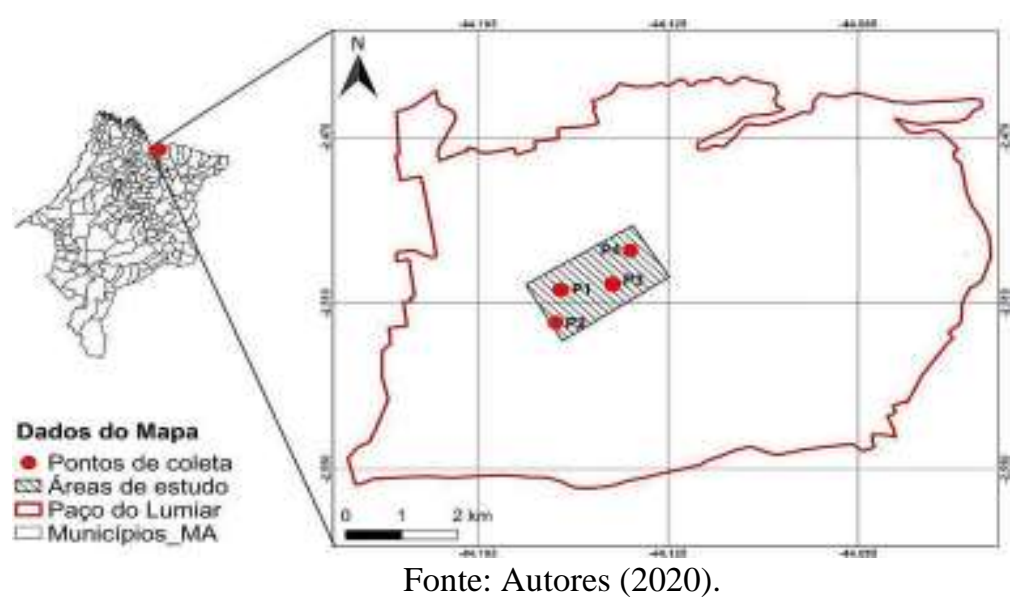

A propriedade é classificada como pequena propriedade rural, possuindo cerca de 40 hectares que equivalem a 1,5 módulos fiscais, sendo o município de Paço do Lumiar, na Vila Nova Canaã, Maranhão, Brasil. Fonte: Autores (2020).

\subsection{Coleta de dados para análise SWOT}

A coleta de dados foi realizada na área de produção com as 06 (seis) famílias produtoras que dividem o espaço, nomeadas por "AF1" a "AF6". Quanto a sua natureza, trata-se de uma Unidade de Produção Agrícola, caracterizada pela propriedade rural e seus meios de produção, capitais, mão-de-obra, investimentos entre outros elementos que a constituem. Entrevistas e questionários foram realizados com todas as famílias de agricultores para obtenção de informações de gestão agrícola e de informações de técnicas de cultivo. Este tipo de entrevista fornece um grau de liberdade ao pesquisador, que faz uso de um roteiro de perguntas, podendo, também, acrescentar outras que julgar necessárias, sem perder a objetividade.

Os dados foram sistematizados e organizados em tabelas e gráficos, onde foram analisadas as estratégias utilizadas na produção familiar e conforme a identificação da matriz de análise SWOT para cada família (Quadro 1).

Quadro 1. Fatores de identificação de análise pela matriz SWOT.

\begin{tabular}{ccc} 
Ambiente & Pontos positivos & Pontos negativos \\
\hline Interno & Forças & Fraquezas \\
& "S" & "W" \\
Externo & Oportunidades & Ameaças \\
& "O" & "T" \\
\hline
\end{tabular}

Fonte: Autores (2020).

Como requisito para a execução da pesquisa de campo, esta pesquisa foi submetida ao Comitê de Ética e Pesquisa (CEP) da Universidade CEUMA e que foi aprovado conforme Certificado de Apresentação para Apreciação Ética (CNAAE) $\mathrm{n}^{\circ}$ 99133718.3.0000.5084. 


\subsection{Coleta, amostra do solo e análises físico-químicas}

Foi utilizado um Global Position System (GPS) Garmin Striker ${ }^{\circledR} 4$ para demarcação da área e os pontos de coleta do solo. As características edafoclimáticas foram caracterizadas no ato da coleta. As amostras de solo foram denominadas de: P1, P2, P3 e P4, onde o ponto P1, corresponde ao "solo leira de alface e cheiro-verde", coordenadas S $02^{\circ} 47^{\prime} 89.8^{\prime}$ " e W $44^{\circ} 17^{\prime}$ 98.1"; P2, "solo leira de couve e rúcula", coordenadas S 02 49' 35.6" e W 44 13' 29.1"; P3 "solo leira de mandioca", S $02^{\circ}$

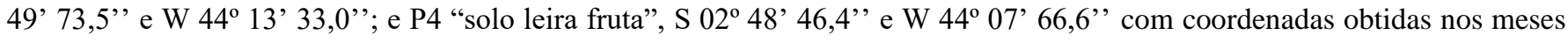
setembro e outubro de 2019. As amostras de solo foram coletadas com um trado de inox, introduzido até $15 \mathrm{~cm}$ de profundidade.

As amostras do solo foram coletadas em triplicata em função do tamanho da área. O material foi homogeneizado e uma porção de aproximadamente $500 \mathrm{~g}$ cada amostra foi isolada em saco plástico e acondicionadas em isopor. Posteriormente, foram submetidas as respectivas análises físico-química: matéria orgânica, carbono orgânico, umidade, granulometria e concentrações dos nutrientes (nitrato e nitrito, fósforo total), conforme preconiza o Manual de Análise de Solos da Empresa Brasileira de Pesquisa Agropecuária Ministério da Agricultura, Pecuária e Abastecimento (Campos, Da Silva, et al., 2005; Donagem et al., 2011; Rheinheimer \& Anghinoni, 2001).

As análises de sedimento (granulometria) foram realizadas pelo método de peneiramento ou combinação de peneiramentos, seguindo as normas da ABNT NBR 7181-84 e método de pipetagem. O pH das amostras foram medidos por (PHmetro de bolso Premium PH60, sensores multiparâmetro HANNA ${ }^{\circledR}$. A matéria orgânica, carbono orgânico, nitrato, nitrito e minerais foram quantificados por incineração e Walkley-Black e Espectrofotômetro (Donagem et al., 2011).

\section{Resultados e Discussão}

\subsection{Perfil socioeconômico dos agricultores familiares da comunidade Canã̃}

A partir da análise dos dados sobre a idade dos agricultores, cerca de $60 \%$ dos produtores pertencem a faixa etária entre (35 a 50 anos). Segundo Neri e colaboradores (2012) a maior taxa de ocupação no meio rural está na faixa etária compreendida ente 40 a 49 anos, onde a maior idade indicada pelos autores foi compatível a idade máxima obtida na pesquisa. Com relação ao sexo dos agricultores observou-se que $60 \%$ são do sexo masculino. Esses resultados corroboram com os obtidos por Neri e colaboradores (2012) que obtiveram uma taxa de $87,57 \%$ da participação masculina nas atividades agrícolas.

Avaliando-se ao grau de escolaridade, a maioria dos membros possui 55\% do ensino médio completo e 16,7\% nível superior, se diferenciando do grau de escolaridade de agricultores familiares na região Nordeste, relatado no Censo Agropecuário (Brasil, 2006). O perfil educacional se elevou, diferente do que ocorria no início do século XX, que anteriormente se limitava ao ensino Fundamental Incompleto. A baixa qualificação das pessoas do campo e a ausência de orientação técnica no decorrer do processo produtivo, também podem implicar em danos econômicos, ambientais e à saúde, devido ao uso inadequado de insumos como, adubos, agrotóxicos e equipamentos agrícolas (de Moura \& Magalhães De Moura, 2016).

Conforme Esquerdo \& Bergamasco(2015), as famílias do Canaã, apresentam um perfil de Agricultor Familiar, seguindo a Lei $n^{\circ} 11.326 / 2006$, cuja propriedade tenha de 1 a 4 módulos fiscais, com a maior parte da renda e mão de obra provenientes da propriedade, a dimensão de um módulo fiscal varia de acordo com o município onde está localizada a propriedade, no Brasil, varia entre 5 a 110 hectares, seguindo a delimitação da Empresa Brasileira de Pesquisa Agropecuária (EMBRAPA) na região de Paço do Lumiar, 1 módulo fiscal corresponde a 30 hectares. Os aspectos socioeconômicos são representados na Tabela 1. 
Tabela 1. Análise socioeconômica das famílias de agricultores referentes à produção de setembro e outubro de 2019.

\begin{tabular}{|c|c|c|c|c|c|c|c|c|}
\hline $\begin{array}{c}\text { Identificação das } \\
\text { Famílias }\end{array}$ & $\begin{array}{l}N^{0} \text { de } \\
\text { filhos }\end{array}$ & $(\%)$ & $\begin{array}{c}\text { Familiares que } \\
\text { ajudam na produção }\end{array}$ & $(\%)$ & $\begin{array}{l}\text { Custo da produção } \\
\text { em reais }(\mathbf{R} \$)\end{array}$ & $\begin{array}{l}\text { Renda bruta } \\
\text { em reais }(\mathbf{R} \$)\end{array}$ & $\begin{array}{l}\text { Mão de obra } \\
\text { contratada }\end{array}$ & $(\%)$ \\
\hline $\mathrm{AF} 1$ & 1 & 10,0 & 1 & 12,5 & 5200 & 7500 & 4 & 40,0 \\
\hline AF 2 & 2 & 20,0 & 2 & 25,0 & 2900 & 2500 & 1 & 10,0 \\
\hline AF 3 & 1 & 10,0 & 1 & 12,5 & 2800 & 2800 & 1 & 10,0 \\
\hline $\mathrm{AF} 4$ & 1 & 10,0 & 2 & 25,0 & 3900 & 6500 & 2 & 20,0 \\
\hline AF 5 & 2 & 20,0 & 1 & 12,5 & 3800 & 6200 & 2 & 20,0 \\
\hline AF 6 & 3 & 30,0 & 1 & 12,5 & 2000 & 1000 & 0 & 0,0 \\
\hline
\end{tabular}

Fonte: Autores (2020).

O número de pessoas envolvidas na produção variou entre $12 \%$ e $25 \%$ constituindo uma baixa força de trabalho no sistema de produção de horticultura, o que explica a contratação de terceiros, $90 \%$ dos agricultores contratam diarista para auxiliar no plantio e/ou na colheita. Isso torna explícito que a força de trabalho é familiar, sendo reforçado quando necessário. O sistema de produção de horticultura é o que mais exige força de trabalho, o que nem sempre é possível suprir com os familiares. Segundo Vargas et al., (2019) cerda de 70\% das unidades familiares empregam mãos-de-obra assalariadas temporária, registrando uma média de 69 dias/homem, representando $11 \%$ de toda a mão-de-obra utilizada, ainda se verifica $1,5 \%$ das unidades utiliza mão-de-obra permanente, na média de 10 dias/homem, algo em torno de $2 \%$ da força de trabalho total mobilizada.

A renda bruta obtida nos estabelecimentos familiares demonstra o potencial econômico e produtivo dos agricultores familiares, que apesar de todas as limitações, não produzem apenas para subsistência, obtendo renda através da produção agropecuária de seus estabelecimentos.

Observando-se a variação de renda tendo as famílias AF1, AF4 e AF5, uma renda bruta superior a 6000 reais, esses valores representam a média mensal de $\mathrm{R} \$$ 6.833,00, já as famílias AF2, AF3 e AF4 renda entre 1.000,00 e 2800,00 reais, demonstra que, mesmo ocupando uma mesma área de trabalho, há uma diferença elevada na lucratividade. O Censo/IBGE de 2006, apresenta o estado do Maranhão com agricultores de baixo poder aquisitivo, , com média por estabelecimento familiar de $\mathrm{R} \$ 2717$, variando entre R\$ 1159 no Nordeste e R \$ 3.315 (IBGE, 2006).

A relação de custos está ligada diretamente ao ganho, por isso mudam com a variação do volume de produção, nesse caso, em específico, também está relacionado como o prejuízo direto para as famílias AF2, AF3, que obtiveram custos bem próximos dos da renda bruta enquanto na família AF6, o custo foi o dobro da renda obtida, confirmando que o investimento na produção, não obteve o retorno desejado. Segundo Neri et al., 2012, o custo de produção está relacionado ao tempo de produção e que a estimativa dos custos está ligada à gestão da tecnologia, ou seja, à alocação eficiente dos recursos produtivos e ao conhecimento dos preços destes recursos.

\subsection{Análise de custo e viabilidade produtiva dos agricultores familiares da comunidade Canaã}

Dentre as culturas observadas, destaca-se cheiro-verde, cebolinha, alface, mandioca, salsinha, mamão e feijão, com diferencial produtivo durante os períodos seco e chuvoso, pois no período chuvoso, há uma grande perda principalmente de hortaliças folhosas. A pluviosidade excessiva, segundo Orivaldo(2008), pode causar impacto na produção de hortaliças folhosas, afetando a qualidade das folhas e de frutas, que não estão sendo cultivadas em sistema protegido. 
O valor teto estabelecido de $\mathrm{R} \$ 600,00$ foi atribuído por meio da média do teto do valor de produção obtidos por meio do relatório e entrevistas com as famílias que informaram este valor apurado como o maior durante os períodos de colheita. Para Guanziroli \& Sabbato, 2014, o Maranhão e Piauí, destacam-se como os de valor de produção por hectare mais baixo, quase dez vezes menor que Alagoas, nesses estados a produção oriunda de grupos não familiares supera o dos familiares, o que deve ser consequência da maior exploração de técnicas de plantio nestes nos demais estados do Nordeste. Na Figura 2 é apresentado o volume da produção de hortaliças, tubérculos e frutas durante o período seco e chuvoso no período em estudo.

Figura 2. Volume de produção de hortaliças, tubérculos, e frutas no período seco (A) e chuvoso (B). O eixo de "y" representa o teto do valor de produção em reais e o eixo de "x" as famílias com suas respetivas culturas de plantio.
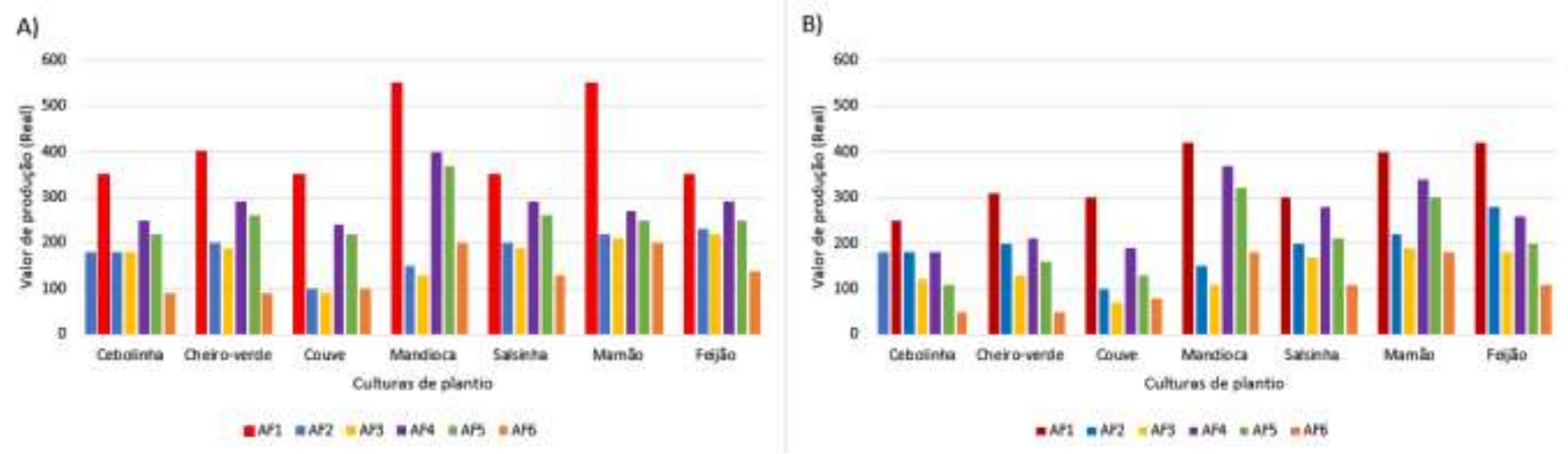

Fonte: Autores (2020).

Foi perceptível uma maior produção nas famílias AF1, AF4 e AF5, tanto no período seco quanto ao chuvoso, as famílias relatam também que os produtos com maior prioridade, são: cebolinha, cheiro verde e alface, por serem consumidas com mais frequência na culinária local e se tratar de hortaliças mais perecíveis com tempo de armazenagem de 1 a 7 dias.

Entres as razões declaradas pelos agricultores para o cultivo das espécies de hortaliças encontradas nas unidades produtivas, estão a demanda de mercado e o conhecimento de cultivo, maior preço, ciclo mais curto da cultura, menor custo de produção e resistência às pragas. Os agricultores se dedicam às hortaliças específicas por apresentarem ciclo curto, consequentemente geram um retorno econômico mais rápido ao produtor e são espécies de fácil adaptação ao clima (Sediyama et al., 2014).

A produção semanal na média da família AF1 foi de 200 maços de cheiro verde, no período seco e 180 maços no período chuvoso, enquanto a família AF6 foi de 70 maços de cheiro verde, no período seco e 40 maços no período chuvoso, se considerarmos a produção semestral somente no período seco, a família AF1 atinge a marca de 4320 maços de cheiro verde produzidos. Levando em consideração que o valor da unidade de maço, atualmente custa $\mathrm{R} \$ 0,70$ teríamos uma renda média bruta de R \$ 3.020,00, apenas com cheiro verde, enquanto a família AF6 teria apenas R \$1.176,00.

$\mathrm{O}$ entendimento sobre a diferença entre a capacidade produtiva entre as famílias, está relacionado a fatores como o manejo do solo, controle de pragas e doenças, mão-de-obra disponível, ausência de assistência técnica e o repasse de conhecimentos técnicos e científicos e demanda de mercado. O diagnóstico dos principais problemas no cultivo de hortaliças no Estado do Maranhão, realizado pela Governo do Estado do Maranhão (2020), relata que as principais culturas produzidas no Estado são mandioca, feijão e folhosas. Certamente, é um desafio produzir hortaliças na região, devido aos problemas com doenças, favorecidos pelos extremos de calor e umidade. Por outro lado, a demanda é alta e crescente e os preços são, na maioria das vezes, muito compensadores (Governo do Maranhão, 2020). 
De acordo com os entrevistados houve um aumento considerável na produção de mandioca, como mostra a Figura 2, que se deu pela mudança no escoamento da produção, pois era feito exclusivamente por feiras e atravessadores, e passou a servir de componente principal da produção de uma cerveja local, agregando valor ao produto e aumentando seu valor.

Entre as etapas que demandam maior custo financeiro e maior tempo no processo de produção de hortaliças, das famílias em estudo, destacam-se, o preparo da área, adubação, semente e irrigação. O preparo de área (88\%) e irrigação (70\%) são as etapas apontadas pelas famílias, que requer maior demanda de tempo, a adubação (80\%) e sementes (75\%), são as duas etapas que demandam maior custo financeiro, e por ter uma menor capacidade financeira as famílias AF2, AF3 e AF6 tem um impacto maior, o que é observado diretamente na sua capacidade produtiva extremamente menor.

Dentre as informações obtidas, metade dos produtores possuem controle diário da produção, com o controle sistematizado, além de manter o equilíbrio da produção, não souberam apresentar o percentual em relação aos anos anteriores, pois esse controle só começou a ser realizado em março 2019, dos meses estudados houve uma melhoria de $12 \%$, outro ponto que se mostrou diferencial foi o cadastro ativo de crédito e cobrança (escrito em caderno e de forma manual), sendo que anteriormente o controle e cobrança era feito por meio do caderno de anotações, extremamente frágil, o que fortificou o controle financeiro, possibilitando a cobrança e reduzindo a inadimplência em $35 \%$.

Destaca-se que foi relatado pelos agricultores familiares, que não comercializam sua produção para as escolas públicas, através do Programa de Aquisição de Alimentos (PAA), criado pelo governo Federal, para destinar a produção dos agricultores familiares locais, pois o valor médio de compra é abaixo do mercado local, gerando, assim, uma desvalorização e, consequentemente, um ganho menor.

Ao longo do trabalho, destacou-se a relação importante que é estabelecida entre a agricultura familiar e o meio ambiente. Partindo dessa análise, os dados apontam que todos dos produtores entrevistados utilizam adubo orgânico, principalmente o de galinha (cama de frango), por ser mais barato e de fácil acesso em média $\mathrm{R} \$ 150,00$ a tonelada, se comparado ao de gado em média R $\$ 250,00$ a tonelada, como meio de adubação para as suas culturas. Isto é necessário para manter a capacidade nutritiva do solo com fertilizantes, premissa que levou a fazer análise do solo, para verificar qual o impacto sofrido. Constatou-se que $90 \%$ dos produtores utilizam produtos químicos, como pesticidas, acaricidas e inseticidas, sendo inseticida caseiro conhecido como "Neem indiano", o mais utilizado.

\subsection{Determinação da caracterização física e química do solo}

Os resultados das variações foram determinados em quatros pontos de coleta na da área de cultivo, determinados a média e desvio padrão, e o Teste de Tukey em nitrito $\left(\mathrm{NO}_{2}\right)$, nitrato $\left(\mathrm{NO}_{3}\right), \mathrm{pH}$, fósforo total $(\mathrm{P})$, magnésio $(\mathrm{Mg})$, cálcio $(\mathrm{Ca})$, carbono orgânico (C org), matéria orgânica (MO) e granulometria, que descreve a proporção de partículas de dimensões distintas componentes do solo, que são: areia, silte, argila e as concentrações de metais totais, cádmio (Cd), manganês (Mn), cobre $(\mathrm{Cu})$, níquel $(\mathrm{Ni})$, chumbo $(\mathrm{Pb})$ e zinco $(\mathrm{Zn})$. As análises físico-químicas do solo foram representadas em uma tabela única (Tabela 2). 
Tabela 2. Análise dos parâmetros físico-químicos em quatro pontos de coleta no solo de cultivo familiar.

\begin{tabular}{|c|c|c|c|c|}
\hline Parâmetros & P1 & $\mathbf{P 2}$ & P3 & P4 \\
\hline $\mathrm{pH}$ & $4,33 \pm 0.05 a$ & $4,16 \pm 0.05 b$ & $3,76 \pm 0.05 c$ & $4,16 \pm 0.05 b$ \\
\hline $\mathrm{NO}_{2}^{-}\left(\mathrm{mg} \cdot \mathrm{L}^{-1}\right)$ & $0,27 \pm 0.01 \mathrm{a}$ & $0,86 \pm 0.01 b$ & $0,92 \pm 0.01 \mathrm{c}$ & $0,38 \pm 0.01 d$ \\
\hline $\mathrm{NO}^{-}\left(\mathrm{mg} . \mathrm{L}^{-1}\right)$ & $1,86 \pm 0,05 a$ & $1,21 \pm 0,12 b$ & $2,82 \pm 0,02 \mathrm{c}$ & $3,91 \pm 0,01 d$ \\
\hline $\mathrm{P}\left(\mathrm{mg} . \mathrm{L}^{-1}\right)$ & $5,53 \pm 0.05 a$ & $4,36 \pm 0.05 b$ & $3,83 \pm 0.05 c$ & $2,33 \pm 0.05 \mathrm{~d}$ \\
\hline $\operatorname{Mg}\left(\mathrm{mg} . \mathrm{L}^{-1}\right)$ & $25,33 \pm 0.57 a$ & $26,66 \pm 0.57 \mathrm{a}$ & $25,33 \pm 0.57 a$ & $45,33 \pm 0.57 b$ \\
\hline $\mathrm{Ca}\left(\mathrm{mg} . \mathrm{L}^{-1}\right)$ & $301.00 \pm 1.00 \mathrm{a}$ & $241.66 \pm 1.52 b$ & $331.33 \pm 1.52 c$ & $361.00 \pm 1.00 \mathrm{~d}$ \\
\hline $\mathrm{C}$ org $(\%)$ & $16.62 \pm 0.02 \mathrm{a}$ & $12.03 \pm 0.02 b$ & $10.63 \pm 0.02 c$ & $11.82 \pm 0.02 \mathrm{~d}$ \\
\hline $\mathrm{MO}(\%)$ & $28.80 \pm 0.02 \mathrm{a}$ & $38.53 \pm 0.25 b$ & $32.60 \pm 0.10 c$ & $79.90 \pm 0.10 \mathrm{~d}$ \\
\hline Areia (\%) & $69.08 \pm 0.01 \mathrm{a}$ & $67.08 \pm 0.01 b$ & $68.82 \pm 0.02 c$ & $68.30 \pm 0.01 d$ \\
\hline Silte (\%) & $28.94 \pm 0.04 a$ & $31.58 \pm 0.01 b$ & $29.85 \pm 0.04 c$ & $28.97 \pm 0.01 \mathrm{a}$ \\
\hline Argila (\%) & $1.40 \pm 0.01 \mathrm{a}$ & $1.37 \pm 0.02 \mathrm{a}$ & $1.39 \pm 0.02 \mathrm{a}$ & $2.74 \pm 0.01 b$ \\
\hline $\mathrm{Cd}\left(\mathrm{mg} . \mathrm{L}^{-1}\right)$ & $0.01 \pm 5,77 \mathrm{e}^{-4} \mathrm{a}$ & $0.11 \pm 5,77 \mathrm{e}^{-4} \mathrm{~b}$ & $0.10 \pm 5,77 \mathrm{e}^{-4} \mathrm{c}$ & $0.01 \pm 5,77 \mathrm{e}^{-4} \mathrm{~d}$ \\
\hline $\operatorname{Mn}\left(m g . L^{-1}\right)$ & $1.31 \pm 1,00 \mathrm{e}^{-3} \mathrm{a}$ & $2.03 \pm 1,00 \mathrm{e}^{-3} \mathrm{~b}$ & $2.13 \pm 1,00 \mathrm{e}^{-3} \mathrm{c}$ & $3.67 \pm 1,00 \mathrm{e}^{-3} \mathrm{~d}$ \\
\hline $\mathrm{Cu}\left(\mathrm{mg} . \mathrm{L}^{-1}\right)$ & $12.21 \pm 0.01 \mathrm{a}$ & $12.12 \pm 0.02 b$ & $11.23 \pm 0.03 c$ & $14.11 \pm 0.01 \mathrm{~d}$ \\
\hline Ni (mg. L $\left.{ }^{-1}\right)$ & $0.13 \pm 1.52 \mathrm{e}^{-4} \mathrm{a}$ & $0.13 \pm 2.64 \mathrm{e}^{-4} \mathrm{~b}$ & $0.13 \pm 2.08 \mathrm{e}^{-4} \mathrm{c}$ & $0.48 \pm 1.52 \mathrm{e}^{-4} \mathrm{~d}$ \\
\hline $\mathrm{Pb}\left(\mathrm{mg} . \mathrm{L}^{-1}\right)$ & $0.06 \pm 1,00 \mathrm{e}^{-3} \mathrm{a}$ & $0.01 \pm 5,77 \mathrm{e}^{-4} \mathrm{~b}$ & $0.02 \pm 1,00 \mathrm{e}^{-3} \mathrm{c}$ & $0.02 \pm 5,77 \mathrm{e}^{-4} \mathrm{c}$ \\
\hline $\mathrm{Zn}\left(\mathrm{mg} . \mathrm{L}^{-1}\right)$ & $1.11 \pm 5.77 \mathrm{e}^{-4} \mathrm{a}$ & $2.81 \pm 1.00 \mathrm{e}^{-3} \mathrm{~b}$ & $3.38 \pm 1.00 \mathrm{e}^{-3} \mathrm{c}$ & $2.03 \pm 1.00 \mathrm{e}^{-3} \mathrm{~d}$ \\
\hline
\end{tabular}

Testes realizados em triplicata e as médias foram seguidas pela mesma letra na linha. Teste de Tukey foi realizado para avaliar as diferenças foram significativas, considerando $\mathrm{p}<0,05$. Fonte: Autores (2020).

As análises de granulométrica das amostras do solo, variando entre os pontos P1, P2, P3 e P4 reforçam a classificação do solo como sendo areia média à fina à siltosa à argilosa, porque podem influenciar as condições ambientais, a fração de areia predominou na quase totalidade dos pontos. O solo foi classificado como areia m. Para Silva et al., (2017) as maiores porcentagens da fração areia em amostras de solos são justificadas pelas características da região. A textura no solo é porosa, o que aumenta o potencial para resíduos de agrotóxicos percolem pelo seu perfil. Entretanto, outras características do ambiente edáfico precisam ser analisadas para determinar a sua capacidade de retenção de contaminantes.

Nos teores percentuais da matéria orgânica os resultados encontrados nos pontos P1 a P4 variaram de 28,80 a 79,90\% o resultado acima de $79 \%$ constata uma intervenção antrópica decorrente do manejo adequado decorrente dos compostos de adubação da região. Para Blainski et al., (2012) a influência vegetal e de resíduos sobre a densidade, porosidade e outros atributos físicos de um solo franco-arenoso sob plantio direto, constata uma melhoria considerável na qualidade física do solo, com diminuição da densidade, em contraste ao aumento de densidade nos tratamentos sem cobertura vegetal.

Com adubação adequada e boas práticas de manejo do solo há um aumento na quantidade de matéria orgânica presente no solo, sendo benéfica para as propriedades físico-químicas, devendo ser aplicada regularmente para manter a produção das culturas (Murakami, 2014). O carbono orgânico encontrados nos pontos de amostragem de P1 a P4 os valores foram de 10.63 a $16.62 \%$, essa semelhança de valores apresentou uma relação positiva com a estabilidade dos complexos organominerais, que se deve ao fato de que a matéria orgânica apresenta uma grande concentração de grupos funcionais de sedimentos areno-siltoso e argiloso. Foi observado na área estudada que na superfície do solo, os teores de Carbono orgânico. O resultam da alta produção de biomassa, através da deposição de adubo orgânico, principalmente o de galinha (cama de frango) e folhas de hortaliças. 
Os resíduos vegetais são inicialmente colonizados por microrganismos e ao mesmo tempo se adsorvem aos minerais. Em P3 teve menor valor de carbono orgânico (10.63\%), que pode ser explicado pela intensidade dos processos de adição de resíduos vegetais com baixas taxas de decomposição na superfície do solo e aumentando seu teor com a profundidade, que segundo Schenato, (2007), o fato de P2 apresentar menor teor, devido à dificuldade de se realizar complexos organominerais que passam a manter os ácidos orgânicos provenientes da decomposição dos resíduos vegetais no solo. Assim, solos argilosos têm menores taxas de decomposição da matéria orgânica e consequentemente maior estabilidade química.

Em geral, não houve uma semelhança estatística apenas as medidas de pH nos pontos 2 e 4 foram iguais. Observando que em todos os pontos o seu solo é muito ácido, isto é, a região é muita arenosa e pobre de nutrientes, o pH não representa, por exemplo, as condições naturais de solos brasileiros, então este solo é corrigido por adubo e outros nutrientes. Os valores encontrados estão dentro do permitido pela (Donagem et al., 2011).

A presença de Nitrito indica a ocorrência de processos biológicos ativos influenciados por poluição orgânica, sendo instável na presença de oxigênio (Bastos, R. K., Bezerra, N. R., Bevilacqua, 2007). Para Rheinheimer \& Anghinoni, (2001), o baixo índice de fosforo encontrado, pode estar associado a adição consecutiva de fertilizantes na camada superficial, ausência de revolvimento e diminuição das taxas de erosão nos nutrientes, saturando a camada superficial e comprometendo as camadas mais profundas.

Aplicações de dejetos líquidos como pesticidas, podem potencializar transferência de fósforo, nitrato e nitrito, por via de escoamento e percolação atingindo concentrações superiores as estabelecidas pela legislação, com grande potencial de contaminação ambiental por eutrofização contribuindo para o aumento dos processos biológicos, contaminando hortaliças mais sensíveis como de couve, alface e cheiro verde.

Dentre os metais pesados mais perigosos o cádmio, demonstrou comportamento semelhante nos quatro pontos de coleta, com teores médios de 0,10 $\pm 5,77$. O cádmio apresentou, valores dentro do limite permitido pela Resolução CONAMA No 420 de 28/12/2009, que define 3,00 mg. $\mathrm{Kg}^{-1}$ passível de investigação. Nos seres humanos, o cádmio possui alta capacidade de se acumular no fígado, rins e ossos (Garcia, 2013). Além do consumo de comidas contaminadas, a exposição a cádmio pode ocorrer através da ingestão de água (Ferreira, 2009).

Um dos elementos mais tóxicos encontrados o chumbo $0,01 \mathrm{mg}$. $\mathrm{L}^{-1}$ a $0,06 \mathrm{mg}$. $\mathrm{L}^{-1}$ com média de $(0,02 \pm 5,90)$, normalmente seu surgimento está associado as práticas agrícolas que envolvem a utilização de fertilizantes, adubos, pesticidas e irrigação, o que responde por uma parcela importante na contaminação ambiental por metais pesados. Pesquisas relacionadas a assimilação de metais pesados por plantas têm constatado que esse metal pode ocasionar consequências negativas relacionadas ao crescimento do vegetal e na germinação de sementes, podendo restringir a produtividade de clorofila e causar danos ao material genético e mudanças do funcionamento enzimático da planta (Ribeiro et al., 2015).

A disponibilidade manganês no solo depende principalmente do $\mathrm{pH}$ e da matéria orgânica presente no solo. Para Campos, Silva, et al., (2005), o manganês é com frequência considerado como um dos elementos traço de menor toxicidade, variando consideravelmente os efeitos adversos, no entanto, quando presente em concentrações elevadas, decorrentes de exposição via oral, pode causar alucinações e doenças do sistema nervoso central.

O cobre é um elemento comum e encontrando em abundância na crosta terrestre, principalmente em solos compostos de decomposição de rochas, não sendo comum encontrar casos de intoxicação por esse tipo de metal. Na matéria orgânica o cobre é retido principalmente pelos ácidos húmicos e fúlvicos, formando complexos estáveis, que exercem um papel importante tanto na mobilidade como na disponibilidade destes para as plantas (Natália et al., 2017).

Também encontrado naturalmente em solos e rochas o níquel é introduzido por meio da degradação de rochas, no solo, analisado está distribuído entre a matéria orgânica como óxido amorfo e a fração argila. Geralmente, a solubilidade do níquel no solo é inversamente relacionada ao pH, isto é, em solos tratados com cal, pode ocorrer uma redução da disponibilidade do 
níquel, alta concentração de níquel observado em solos, geralmente é proveniente de atividades humanas (Makusa, 2012). O cádmio é quase sempre encontrado associado ao $\mathrm{Zn}, \mathrm{Pb}$ e minério de $\mathrm{Cu}$ (Garcia, 2013).

As concentrações desses metais no solo se caracterizam pela quantidade de produtos químicos que liberam para corrigir o solo, o que termina comprometendo as hortaliças. Foi relatado, entre os agricultores familiares, uma quantidade muito grande de fungos de cor branca na raiz e caule do mamão, e que estes adicionavam Hidróxido de Cobre técnico oxiquímica.

\subsection{Dados de análise SWOT e modelo de planejamento}

Analisando as informações obtidas durante as entrevistas com os agricultores familiares, desenvolveu-se o modelo de planejamento estratégico, contemplando as forças, fraquezas, oportunidades e ameaças, conforme demonstra a Quadro 2.

Quadro 2. Critérios utilizados como parâmetro de avaliação por análises SWOT.

\begin{tabular}{ll} 
FORÇAS & FRAQUEZAS \\
\hline Utilização de estufas; & Recursos financeiros limitados; \\
Apoio técnico; & Baixa Produção; \\
Maquinário próprio; & Dificuldade de acesso; \\
Venda direta; & Pragas que prejudicam a plantação; \\
Beneficiamento da produção; & Solo arenoso \\
Controle financeiro. & Mão de obra contratada \\
OPORTUNIDADES & AMEAÇAS \\
\hline Início do período chuvoso; & Infraestrutura; \\
Divulgação em redes sociais; & Grandes produtores externos; \\
Aumento de lanchonetes e bares; & Falta de assistência do poder público; \\
Indicação dos próprios clientes; & Burocracia liberar licença dos órgãos; \\
Incentivo à produção local. & Preço muito abaixo dos produtos concorrentes. \\
\hline
\end{tabular}

Fonte: Autores (2020).

Para Machado \& Souza (2006) o objetivo da análise é possibilitar que a empresa se posicione para tirar vantagem de determinadas oportunidades do ambiente e evitar ou minimizar as ameaças ambientais. Com isso, a empresa tenta enfatizar seus pontos fortes e moderar o impacto de seus pontos fracos. Dessa forma foi criada a Matriz SWOT da unidade de produção agrícola por meio da identificação das forças e fraquezas; e, das oportunidades e ameaças.

Quanto à utilização de sistemas de proteção, como "Força" nas AF1, AF4 e AF5 foi verificado do tipo "Abrigo", nome técnico para estufa, apesar de gerar um custo elevado, pois este investimento pode alcançar R \$ 2.000,00 (dois mil reais) a R \$ 3.000,00 (três mil reais), trazendo vários benefícios, resultando nas seguintes melhorias: impede a proliferação de pragas do solo e de insetos; o cultivo fora de época, possibilitando assim cultivo de hortaliças em locais que normalmente possuem condições inadequadas; economia na irrigação com o processo de fertirrigação, que é a aplicação do adubo junto com a água, aumentando o rendimento dos fertilizantes e no aumento da qualidade e por estarem em clima apropriado.

A grande "Força" observada nas famílias AF1, AF4 e AF5 foi a aquisição de máquinas e equipamentos para realizar o beneficiamento da produção, personalizando e diferenciando seus produtos dos demais no mercado. Como consequência, gerou a criação de um canal de venda diário, através de ferramentas de Marketing para bares, restaurantes e até o consumidor final, modificando toda sua relação com o mercado, diferente da maior parte dos produtores que vende somente em feiras nos fins de semana. As maiores "Fraquezas" relatadas por todas as famílias foram: dificuldade de acesso, mão de obra contratada e solo pobre de nutrientes.

Nas “Ameaças”, foram relacionadas como aspectos que representam riscos para a manutenção do sistema de produção, como relata o produtor AF4, com relação aos grandes produtores, a falta de assistência do poder público e a burocracia. 
Nas entrevistas todos os produtores reclamaram da questão burocrática para emissão de notas fiscais, sendo que 50\% das famílias estão com a documentação pronta para essa emissão, e ainda assim tiveram que contratar um contador, aumentando ainda mais seus custos na formalização do negócio. Os entrevistados reclamam também da falta de incentivo e facilidade para entrar em programas de assistência, no que se constatou que apenas $30 \%$ deles chegou a conseguir recursos do Banco do Nordeste, por meio de empréstimo, e que estão tendo dificuldade de pagar, mesmo com todo o período de carência. $\mathrm{O}$ acesso das vias ainda é realizado por estradas carroçais, sem sinalização ou mesmo linhas de transporte coletivo regular, o que aumenta ainda mais o isolamento e a cobrança de preços abusivos para fretes e viagens.

Para Carvalho \& Lima, (2015), com o passar dos anos, o agronegócio passou por vários tipos de mudanças, e um dos principais fatores responsáveis por esse processo foi o aumento da competitividade, que fez com que o processo de gestão fosse aperfeiçoado para realizar os negócios de uma forma mais dinâmica e ágil.

A partir dos resultados obtidos na Análise SWOT, foi possível traçar um Feedback aos agricultores e promover um adequado Planejamento Estratégico conforme a Figura 3.

Figura 3. Fluxograma do planejamento estratégico.

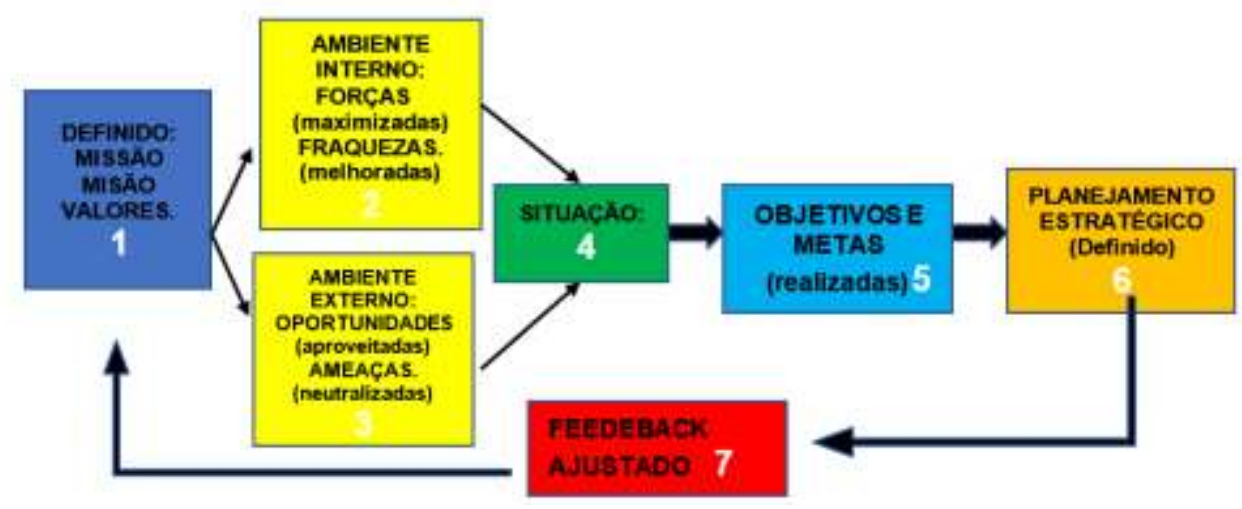

Fonte: Autores (2020).

O planejamento estratégico elaborado para as famílias da Comunidade Canaã foi desenvolvi do conforme as análises SWOT. A missão visa executar as atividades agrícolas com eficiência e eficácia produzindo alimentos de qualidade para o consumo próprio e comercialização dos produtos. A visão tem como objetivo aumentar a produtividade com os custos reduzidos e incorporação de novas tecnologias. Os valores estão relacionados às atividades com responsabilidade social utilizando-se práticas sustentáveis. As práticas baseadas nas análises SWOT poderão alcançar objetivos, como aumento da produtividade e redução de desperdícios, melhoria no poder de negociação, fechamento de parcerias com novos compradores, desenvolvimento de um sistema de controle financeiros.

\section{Considerações Finais}

Através da análise do mercado foi possível observar quais culturas oferecem uma maior rentabilidade e de que forma o produtor pode aplicar maior esforço financeiro na produção destas. Fazendo um comparativo das famílias que utilizam as técnicas com que ainda permanecem na forma tradicional, podemos perceber que essa é a margem entre lucro ou prejuízo. A utilização das ferramentas gerenciais proporciona o entendimento amplo de como funciona a produção de hortaliças e de que maneira pode contribuir com a construção de estratégias para melhoria do desempenho operacional. Com o auxílio da ferramenta de análise SWOT, foi possível demonstrar que planejamento administrativo é essencial para fomentar a tomada de decisão e consequente obtenção dos resultados fortalecendo a ideia do planejamento estratégico. 


\section{Agradecimentos}

Os autores agradecem ao Programa de Pós-graduação em Meio Ambiente da Universidade CEUMA.

\section{Referências}

Antunes, H., Ana, D. S., \& Costa, S. (2001). Conflitos socioambientais e estratégias de defesa do território. 159-172. https://sigaa.ufma.br/sigaa/public/docente/producao.jsf?siape=1096955

Baiardi, A., \& Alencar, C. M. M. de. (2014). Agricultura familiar, seu interesse acadêmico, sua lógica constitutiva e sua resiliência no Brasil. Revista de Economia e Sociologia Rural, 52, 45-62. https://doi.org/10.1590/S0103-20032014000600003

Bastos, R. K; Bezerra, N. R.; Bevilacqua, P. D. (2007). Water Safety Plans: New Paradigms in Water Quality Control for Human Consumption in Consistency with Brazilian Legislation.

Biassio, A. De, \& Silva, I. C. (2015). Análise swot como ferramenta para avaliação da agrobiodiversidade em sistemas tradicionais de produção nos municípios de antonina e morretes/pr swot analysis as a tool for assessing the agrobiodiversity in traditional production systems in the municipalities of antonina and morretes / PR. In Scientia Agraria (Vol. 16, Issue 2). https://www.redalyc.org/pdf/995/99538307003.pdf

Blainski, É., Tormena, C. A., Guimarães, R. M. L., \& Nanni, M. R. (2012). Qualidade física de um latossolo sob plantio direto influenciada pela cobertura do solo. Revista Brasileira de Ciência Do Solo, 36(1), 79-87. https://doi.org/10.1590/S0100-06832012000100009

Brasil. (2020). Perfil da Agropecuária Maranhense. 2020. https://sigite.sagrima.ma.gov.br/wp-content/uploads/2021/05/PERFIL-DA-AGROPECUÁRIA2020.pdf

Lei no 11.326,24/07/2006 (2006). http://www.planalto.gov.br/ccivil_03/_Ato2004-2006/2006/Lei/L11326.htm

BRASIL. (2009). Resolução CONAMA $n^{\circ} 420$ de 28/12/2009 - Federal - LegisWeb. https://www.legisweb.com.br/legislacao/?id=111046

Campos, M. L., Da Silva, F. N., Furtini Neto, A. E., Guimarães Guilherme, L. R., Marques, J. J., \& Antunes, A. S. (2005). Determination of cadmium, copper, chromium, nickel, lead and zinc in rock phosphates. Pesquisa Agropecuaria Brasileira, 40(4), 361-367. https://doi.org/10.1590/s0100-204x2005000400007

Campos, M. L., Silva, F. N. da, Furtini Neto, A. E., Guilherme, L. R. G., Marques, J. J., \& Antunes, A. S. (2005). Determinação de cádmio, cobre, cromo, níquel, chumbo e zinco em fosfatos de rocha. Pesquisa Agropecuária Brasileira, 40(4), 361-367. https://doi.org/10.1590/s0100-204x2005000400007

Carlos, S. de M., Cunha, D. A. da, \& Pires, M. V. (2019). Conhecimento sobre mudanças climáticas implica em adaptação? Análise de agricultores do Nordeste brasileiro. Revista de Economia e Sociologia Rural, 57(3), 455-471. https://doi.org/10.1590/1806-9479.2019.187600

Carvalho, T. M. De, \& Lima, P. F. De. (2015). Análise econômica dos tributos no agronegócio: custo de produção ou custo de transação. Custos $e$ @ gronegócio on Line, 11(1), 71-95.www.custoseagronegocioonline.com.br

Cláudia Cardoso Corrêa, M., \& Rosa Marques, A. (2017). O processo de implantação da Termelétrica do Itaqui, São Luís-MA e a sua influência na dinâmica territorial da Vila Nova Canaã, Paço do Lumiar-MA. Revista Campo-Território, 12(28), 203-233. https://doi.org/10.14393/rct122810

Cláudia, M., Corrêa, C., \& Soares Diniz, J. (n.d.). Do território à reterritorialização: o caso da Vila Residencial Nova Canaã, Paço do Lumiar-MA.

de Moura, A. M. M., \& Magalhães De Moura, A. M. (2016). Governança Ambiental no Brasil: instituições, atores e políticas públicas. In Ipea. http://repositorio.ipea.gov.br/handle/11058/6800

De, T., \& Morais, J. (2017). Grandes Empreendimentos e Comunidades Tradicionais: implicações subjetivas em famílias deslocadas compulsoriamente. https://tedebc.ufma.br/jspui/bitstream/tede/2524/2/TAMIRESMORAIS.pdf

Donagem, G. K., Campos, D. V. B. de, Calderano, S. B., Teixeira, W. G., \& Viana, J. H. M. (2011). Manual de métodos de análise de solo. - Portal Embrapa. https://www.embrapa.br/busca-de-publicacoes/-/publicacao/990374/manual-de-metodos-de-analise-de-solo

Esquerdo, V. F. de S.-, \& Bergamasco, S. M. P. P. (2015). Políticas públicas para a agricultura familiar brasileira: um estudo sobre o Pronaf nos municípios do circuito das Frutas-SP. Extensão Rural, 22(1), 09-35. https://doi.org/10.5902/2318179614539

FAJNZYLBER, P.; SARTI, F.; LEAL, J. P. G. (1993). Estudo da competitividade da indústria brasileira: sistema de indicadores da competitividade. Papirus. https://scholar.google.com.br/scholar?q=Estudo+da+Competitividade+da+Indústria+Brasileira\%3A+sistema+de+indicadores+da+competitividade\&btnG=\&hl $=$ pt-BR\&as_sdt=0\%2C5\#1

Ferreira, G. F. (2009). Universidade Federal Do Recôncavo Da Bahia Centro De Ciências Agrárias , Ambientais E Biológicas Programa De Pós-Graduação Em Ciências Agrárias. Universidade Federal Do Recôncavo Da Bahia (Dissertação Mestrado), 1-84.

Garcia, P. R. (2013). Piracicaba 2013.

Guanziroli, C. E., \& Sabbato, A. Di. (2014). EVolução da agricultura familiar nordestina: uma análise comparativa entre os dois censos agropecuários Evolution of northeast family farm: a comparative analysis between two agricultural census Carlos Enrique Guanziroli. Revista Econômica Do Nordeste, 2014(5), 80-91. https://www.bnb.gov.br/revista/index.php/ren/article/view/501

IBGE. (2006). Censo Agropecuário 2006 - Agricultura Familiar - Primeiros resultados. In Censo Agropecuário. https://biblioteca.ibge.gov.br/index.php/biblioteca-catalogo?id=750\&view=detalhes

Joffre, O., \& Simon, E. (2012). Gestão e práticas socialmente responsáveis na cooperação agrícola. Revista de Administração de Empresas, 52(2), 193-203. 


\section{https://doi.org/10.1590/S0034-75902012000200006}

Machado, D. G., \& Souza, M. A. de. (2006). Análise das relações entre a gestão de custos e a gestão do preço de venda: um estudo das práticas adotadas por empresas industriais conserveiras estabelecidas no rs. Revista Universo Contábil, 2(1), 42-60. http://repositorio.furg.br/handle/1/848

Makusa, G. P. (2012). State of the Art Review Soil Stabilization Methods and Materials in Engineering Practice. Luleå University of Technology, Luleå, Sweden, 1-30. http://urn.kb.se/resolve?urn=urn:nbn:se:ltu:diva-24093

MINTZBER. (2007). Safári de estratégia: um roteiro pela selva do planejamento estratégico. Revista de Ciências Da Administração : RCA, 9(18), 183-184. https://doi.org/10.5007/1647

Moreira, J. F. (2014). Expressões do Desenvolvimento no Porto do Itaqui: reconfiguração territorial, exploração e lucro 1 Jadeylson Ferreira Moreira (UFMA/Brasil) 1 .

Murakami, L. Y. (2014). Dissipação do fungicida fluopicolide em neossolo e latossolo por meio de técnicas radiométricas e cromatográficas [USP]. http://repositoriobiologico.com.br//jspui/handle/123456789/279

Natália, D., Almeida, O. De, Maria, L., Oliveira, M. De, Silva, B., Bezerra, U. A., Farias, M. D. O., Lúcia, A., \& Candeias, B. (2017). ANálise das bacias hidrográficas do rio brígida, rio terra nova e grupo de bacias de pequenos rios interiores 9 ( gi 9 ) de pernambuco usando índices de vegetação e de umidade. 9, 2-6. https://www.researchgate.net/publication/323525500_Analise_das_bacias_hidrograficas_do_rio_brigida_rio_terra_nova_e_grupo_de_bacias_de_ pequenos_rios_interiores_9_gi9_de_pernambuco_usando_indices_de_vegetacao_e_de_umidade

Neri, M. C., Melo, L. C. C. de, \& Monte, S. dos R. (2012). Superação da pobreza e a nova lasse média no campo. 214. https://bibliotecadigital.fgv.br/dspace/handle/10438/19371

Orivaldo, B. (2008). Mudanças climáticas e suas consequências na agricultura. http://www.infobibos.com/Artigos/2008_4/MudancasClimaticas/index.htm

Parizotto Seidler, E., \& Fritz Filho, L. F. (2016). A EVolução da agricultura e o impacto gerado pelos processos de inovação: um estudo de caso no município de coxilha-rs. Economia e Desenvolvimento, 28(1), 388-409. https://doi.org/10.5902/1414650921316

Rheinheimer, D. dos S., \& Anghinoni, I. (2001). Distribution of inorganic phosphorus fraction in soil management systems. Pesquisa Agropecuaria Brasileira, 36(1), 151-160. https://doi.org/10.1590/s0100-204x2001000100019

Ribeiro, E. S., Pereira, M. P., de Castro, E. M., Baroni, G. de R., Corrêa, F. F., \& Pereira, F. J. (2015). Relationship between root anatomy on the uptake, storage and tolerance to lead of Echinodorus grandiflorus. Revista Brasileira de Engenharia Agricola e Ambiental, 19(6), 605-612. https://doi.org/10.1590/1807-1929/agriambi.v19n6p605-612

Schenato, R. B. (2007). Teor de carbono em solos arenosos: comparativo... - Google Acadêmico. https://scholar.google.com.br/scholar?hl=ptBR\&as_sdt=0,5\&cluster $=3276962763496071841$

Sediyama, M. A. N., Dos Santos, I. C., \& De Lima, P. C. (2014). Cultivo de hortaliças no sistema orgânico. Revista Ceres, 61, 829-837. https://doi.org/10.1590/0034-737X201461000008

Silva, M. R. C., Da Silva, L. V., Barreto, L. N., Rodrigues, E. H. C., De Miranda, R. de C. M., Bezerra, D. S., \& Pereira, D. C. A. (2017). Qualidade da Água da Bacia do Rio Pindaré, nos trechos correspondentes aos Municípios de Pindaré- Mirim, Tufilândia e Alto Alegre no Estado do Maranhão. Águas Subterrâneas, 31(4), 347. https://doi.org/10.14295/ras.v31i4.28929

Silva, P. B., Pereira, P. E., Diretor-Executivo, N., Da, S., Côrtes, C., \& Tai, D. W. (2008). Presidente da República Luiz Inácio Lula da Silva Ministro do Planejamento, Orçamento e Gestão INSTITUTO BRASILEIRO DE GEOGRAFIA E ESTATÍSTICA-IBGE.

Thiago, F., Kubo, E. K. de M., Pamplona, J. B., \& Farina, M. C. (2020). Estilo de gestão de produtores rurais. Revista de Economia e Sociologia Rural, 58(2). https://doi.org/10.1590/1806-9479.2020.188254

Valarini, P. J., Oliveira, F. R., Schilickmann, S. de F., \& Poppi, R. J. (2011). Qualidade do solo em sistemas de produção de hortaliças orgânico e convencional. Horticultura Brasileira, 29(4), 485-491. https://doi.org/10.1590/S0102-05362011000400007

Vargas, M. D. de, Seabra Júnior, S., De Oliveira, K. C. L., \& Ruiz, C. G. L. (2019). Análise socioeconômica hortícola na comunidade Vale do Sol II em Tangará da Serra - MT. Agricultura Familiar: Pesquisa, Formação e Desenvolvimento, 12(2), 55. https://doi.org/10.18542/raf.v12i2.7332

Wollmann, C. A., \& Galvani, E. (2013). Zoneamento agroclimático: linhas de pesquisa e caracterização teórica-conceitual. Sociedade \& Natureza, 25(1), 179_ 190. https://doi.org/10.1590/S1982-45132013000100014 